\title{
EFEKTIFITAS KAHOOT BAGI GURU DALAM PEMBELAJARAN DI SEKOLAH DASAR
}

\author{
Herwina Bahar ${ }^{1}$, Dewi Setiyaningsih ${ }^{2}$, Laily Nurmalia ${ }^{3 *}$, Linda Astriani ${ }^{4}$ \\ ${ }^{1,2,3,4}$ Program Studi Pendidikan Guru Sekolah Dasar \\ Fakultas Ilmu Pendidikan, Universitas Muhammadiyah Jakarta \\ Jl. KH. Ahmad Dahlan, Ciputat, Cireundeu, Ciputat Tim, Kota Jakarta Selatan, Daerah Khusus \\ Ibukota Jakarta 15419 \\ Email: *laily.nurmalia@gmail.com
}

Received: Juni 2020; Accepted : Juni 2020; Published : Juli 2020

\begin{abstract}
Abstrak
Teknologi merupakan bagian yang sangat penting dalam kehidupan manusia, salah satunya pada bidang Pendidikan. Pemakaian teknologi dalam pembelajaran dengan menggunakan kemajuan IT dimaksudkan agar kegiatan pembelajaran lebih efektif salah satunya adalah Kahoot. Penelitian ini bertujuan untuk melihat apakah media pembelajaran berbasis teknologi Kahoot dinyatakan efektif digunakan oleh para guru di sekolah dasar di Sukabumi Jawa Barat, yang mana sebelumnya masih menerapkan tes atau kuis secara lisan maupun tertulis. Metode yang digunakan yakni kualitatif, data yang dikumpulkan melalui wawancara dan menyebarkakn kuesioner dengan objek penelitian yaitu guru sekolah dasar di Sukabumi Jawa Barat. Hasil penelitian menyatakan bahwa media pembelajaran berbasis teknologi Kahoot efektif digunakan oleh guru Sekolah Dasar di Sukabumi Jawa Barat.
\end{abstract}

Kata Kunci: Kahoot, Guru, Sekolah Dasar

\section{Abstract}

Technology is a very important part of human life, one of which is in the field of Education. The use of technology in learning by using IT advancements is intended to make learning activities more effective, one of which is Kahoot. This study aims to see whether Kahoot technology-based learning media are declared to be effectively used by teachers in elementary schools in Sukabumi, West Java, who had previously applied oral or written tests or quizzes. The method used is qualitative, data collected through interviews and questionnaires with the object of research are elementary school teachers in Sukabumi, West Java. The results of the study stated that Kahoot technology-based learning media were effectively used by elementary school teachers in Sukabumi, West Java.

Keywords: Kahoot, Teacher, Elementary School

\section{Latar Belakang Masalah}

Teknologi informasi dan komunikasi atau TIK pada zaman sekarang sangat dibutuhkan oleh setiap masyarakat baik itu orang dewasa maupun anak-anak [1]. Saat ini seorang pengajar wajib mempunyai kemampuan dalam memakai dan menyiapkan bahan ajar di suatu kegiatan pembelajaran, hal ini diutamakan yang bisa diakses oleh peserta didik. Pembelajaran e-learning 
dapat memberikan pengalaman yang luas kepada peserta didik. Pembelajaran dengan menggunakan penerapan IT akan berdampak pada profesionalisme seorang pengajar, oleh karena itu kemampuan pemahaman guru harus benar-benar ditingkatkan agar guru dapat memfasilitasi pembelajaran dengan sebaik-baiknya, kompetensi guru perlu diperhatikan [2] sehingga profesionalisme guru sangat penting [3]. Jika seorang guru sudah bisa menguasai pemahaman tersebut maka akan memberikan kompetensi baru terhadap peserta didiknya. Akan tetapi, ada hal yang harus ditekankan bahwa pemakaian teknologi hanya sebagai alat pelengkap atau pendukung pelaksanaan pembelajaran, seorang guru tetap wajib mengimplementasikan tugasnya sebagai seorang pengajar yang professional. Seorang guru professional tidak hanya dituntut untuk menguasai materi pembelajaran yang akan disampaikan kepada peserta didiknya, akan tetapi juga harus mampu mengembangkan dan memanfaatkan media pembelajaran agar pencapaian hasil belajar sesuai dengan standar kompetensi.

Menurut John Renold Siregar [4] media pembelajaran merupakan salah satu komponen penting dan tidak terpisahkan dari keseluruhan proses pembelajaran dalam semua program dan jenjang, sehingga keterampilan untuk mengembangkan dan memanfaatkan media pembelajaran amat dibutuhkan oleh seorang guru yang professional. Menurut Munadi [5] fungsi utama media pembelajaran adalah sebagai sumber belajar. Adapun tujuan media pembelajaran adalah mengefektifkan proses komunikasi pembelajaran sehingga tercapai tujuan yang diinginkan atau adanya perubahan tingkah laku. Menurut Azhar [6] pemakaian media dalam pembelajaran banyak memberikan manfaat pada proses pembelajaran. Dilihat dari manfaat, pemakaian media pembelajaran dalam proses belajar mengajar dapat membangkitkan keinginan dan minat yang baru, membangkitkan motivasi dan rangsangan kegiatan belajar dan bahkan membawa pengaruh psikologis terhadap siswa.

Media yang dapat digunakan dalam pembelajaran di sekolah yakni memanfaatkan teknologi dalam bidang Pendidikan digunakan untuk menunjang proses pembelajaran dan membantu guru agar lebih mudah dalam mengajarkan materi kepada para siswa [7]. Dengan memanfaatkan teknologi yang ada, pembelajaran akan lebih menarik dan siswa semakin semangat dalam belajar. Salah satu teknologi yang berbasis media pembelajaran adalah Kahoot. "Kahoot!" merupakan website edukatif yang pada awalnya diinisiasi oleh Johan Brand, Jamie Brooker dan Morten Versvik dalam sebuah joint project dengan Norwegian University of Technology and Science pada Maret 2013 [8]

Kahoot merupakan salah satu media pembelajaran online yang berisikan kuis dan game. Kahoot juga dapat diartikan sebagai media pembelajaran interaktif karena kahoot dapat digunakan dalam kegiatan belajar mengajar seperti mengadalan pre-test, post-test, latihan sola, penguatan materi, remedial, pengayaan dan sebagainya. Salah satu syarat untuk membuat kahoot adalah memiliki akun gmail atau akun lainnya. Kahoot memiliki empat fitur yaitu game, kuis, diskusi dan survey. Untuk game, bisa dibuat jenis pertanyaan dan menentukan jawabannya serta waktu yang digunakan untuk menjawab pertanyaan tersebut. Uniknya, jawaban nantinya akan diwakili oleh gambar dan warna. Peserta diminta untuk memilih warna atau gambar yang mewakili jawaban yang tepat. Selain mencari jawaban yang tepat. Peserta harus memastikan tidak salah sentuh (klik) ketika memilih jawaban. "Kahoot!" memiliki dua alamat website yang berbeda yaitu https://kahoot.com/ untuk pengajar dan https://kahoot.it/ untuk pembelajar. [8] Kahoot juga sudah tersedia dalam bentuk aplikasi di handphone yang bisa di download dnegan bebas biaya di playstore. Kahoot dapat diakses dan digunakan secara gratis, termasuk semua fitur-fitur yang ada di dalamnya. Platform Kahoot dapat digunakan untuk beberapa bentuk asesmen diantaranya kuis online, survei, dan diskusi dimana ketiganya memiliki cara yang 
bermacam-macam untuk dimainkan. Diperlukan koneksi internet untuk dapat memainkan game ini. Kahoot dapat dimainkan secara individu, meskipun demikian yang menjadi desain utamanya adalah permainan secara berkelompok [9]. Aplikasi Kahoot sebagai platform teknologi pembelajaran mengkombinasikan pengalaman evaluasi pembelajaran dengan game interaktif dan dilengkapi system monitoring aktifitas para peserta didik [10] . Inovasi platform Kahoot ini juga mampu membantu aktifitas evaluasi pembelajaran menjadi menarik, interaktif, kondusif dan mudah dalam memonitoring hasil belajar [11]. Dan juga teknologi informasi dan komunikasi atau TIK pada zaman sekarang sangat dibutuhkan oleh setiap masyarakat baik itu orang dewasa maupun anak-anak [1]

Kahoot juga memiliki kelebihan sebagai media pembelajaran yakni suasana kelas dapat lebih menyenangkan, anak-anak dilatik untuk mengguanakn teknologi sebagai media untuk belajar, dan anak-anak di latih kemampuan motoriknya dalam pengoperasian Kahoot. Selain kelebihan, Kahoot juga memiliki kelemahan sebagai media pembelajaran yaitu tidak semua guru yang update dengan teknologi, fasilitas sekolah kurang memadai, anak-anak mudah terkecoh untuk membuka hal lainnya, terbatarnya jam pertemuan di kelas, tidak semua guru memiliki waktu untuk mengatur menyusun rancangan pembelajaran dengan Kahoot.

Penggunaan Kahoot biasanya digunakan untuk penilaian formatif, untuk memantau setiap kemajuan siswa terhadap tujuan pembelajaran, mengidentifikasi kekuatan dan kelemahan, dan untuk mengidentifikasi daerah-daerah di mana siswa akan mendapatkan manfaat lebih dari satu pembelajaran, lebih menantang kesempatan belajar, atau review dari pengetahuan dasar, pengguna lebih berpengalaman juga mengitegrasikan Kahoot ke dalam kurikulum mereka untuk memperkenalkan topik baru, meningkatkan retensi fakta-fakta baru, merevisi sebelum ujian, kelas tantangan di seluruh dunia, pendapat survei, mengumpulkan wawasan, memfasilitasi diskusi, atau untuk menghargai dan mengembalikan energi peserta didik dalam belajar. Bermain game Kahoot dirancang untuk pembelajaran social, dengan peserta didik yang berkumpul di sekitar layer umum. Dilingkungan kelas yang khas, ini akan menjadi Smart Screen, papan tulis interaktif atau monitor computer. Banyak Kahoot juga dimainkan menggunakan berbagai layer alat seperti Skype, Appear in dan Google Hangouts.

Sehingga guru dituntut untuk dapat menggunakan teknologi salah satunya dapat menggunakan media pembelajaran berbasis teknologi yaitu Kahoot. Kahoot dapat bermanfaat dalam proses belajar mengajar di kelas. Oleh sebab itu, menurut peneliti diperlukan tindakan sebuah penelitian yang meneliti tentang apakah Kahoot efektif digunakan oleh guru. Sehingga peneliti melakukan penelitian tentang Efektivitas Kahoot Bagi Guru Dalam Pembelajaran di Sekolah Dasar

\section{Masalah}

Pada penelitian ini memiliki permasalahan dalam ruang lingkup besar yaitu; apakah media pembelajaran teknologi Kahoot sudah diketahui oleh semua guru, apakah media pembelajaran teknologi Kahoot dapat meningkatkan kinerja guru, dan apakah media pembelajaran berbasis teknologi Kahoot dapat efektif digunakan oleh para guru. Oleh karena itu masalah program pengabdian ini dirumuskan menjadi apakah media pembelajaran berbasis teknologi Kahoot efektif digunakan oleh para Guru Sekolah Dasar di Sukabumi Jawa Barat?

\section{Metode}

Metode penelitian yang menggunakan di penelitian ini ialah pendekatan kualitatif. Pendekatan kualitatif yaitu pendekatan yang berdasarkan pada filsafat post positivism, 
sedangkan untuk meneliti pada objek alamiah, dimana peneliti adalah sebagai instrument kunci, Teknik pengumpulan data dilakukan dengan cara triangulasi atau gabungan. Analisis data bersifat induktif atau kualitatif, dan hasil penelitian lebih menekankan makna daripada generalisasi. Metode penelitian menggunakan adalah metode survei Populasi penelitian ini sebanyak 80 guru yang terdiri dari 6 sekolah, dan penentuan sampel menggunakan teknik random sampling, diperoleh 4 sekolah dengan jumlah sampel 60.

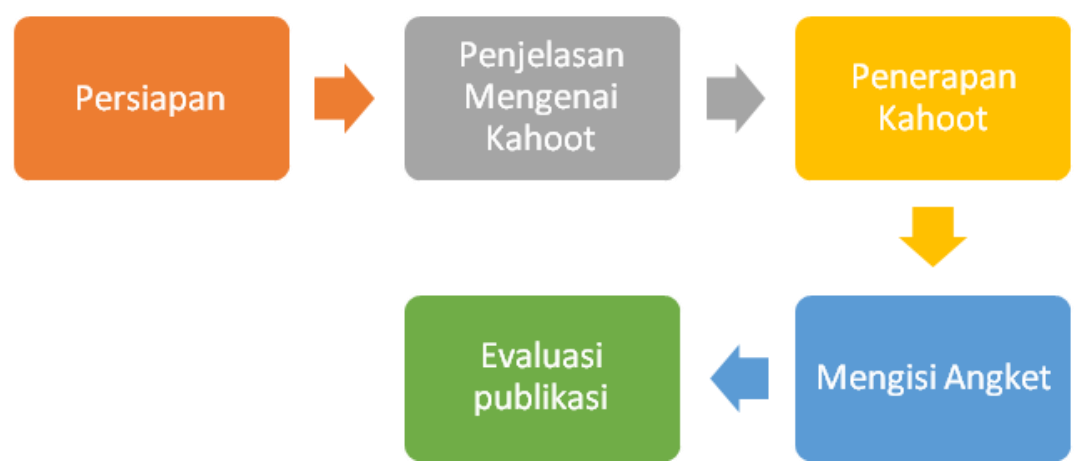

Gambar 1. Diagram Alur Kegiatan

Gambar diagram alur kegiatan yang dilaksanakan meliputi; (1) Persiapan; sebelum dating ke sekolah peneliti melakukan persiapan alat-alat yang akan dibawa saat penelitian seperti membawa laptop, angket, dan LCD. (2) Penjelasan Mengenai Kahoot; peneliti menjelaskan kepada para guru mengenai media pembelajaran teknologi Kahoot, dari apa itu Kahoot, manfaat Kahoot hingga cara menggunakan Kahoot, serta melakukan sesi tanya jawab. (3) Penerapan Kahoot; setelah para guru mengetahui Kahoot secara teori, guru menyiapkan handphone masingmasing dan mengikuti arahan dari peneliti cara penggunaan Kahoot serta di bombing oleh para peneliti. (4) Mengisi angket; setelah para guru selesai guru diminta untuk mengisi angket. (5) Evaluasi publikasi; setelah penelitian selesai dilaksanakan dan dibuat laporan akhir maka penelitian ini akan di publikasikan ke jurnal pengabdian masyarakat.

\section{Hasil dan Pembahasan}

Pada penelitian ini untuk menguji apakah media pembelajaran berbasis teknologi Kahoot efektif digunakan oleh para guru Sekolah Dasar di Sukabumi Jawa Barat. Peserta pelatihan ini berjumlah 11 orang peserta yang mewakili beberapa sekolah dasar yang ada di Kota Sukabumi Jawa Barat. Saat peneliti pertama kali mendatangi ke empat Sekolah Dasar di Sukabumi dan memberikan instrument yang harus diisi oleh guru.

Tabel 1. Hasil Survey pengetahuan Guru tentang Aplikasi Kahoot

\begin{tabular}{l|l|l|l|l}
\hline No & Pertanyaan & Ya & Tidak & Total \\
\hline \hline 1. & $\begin{array}{l}\text { Apakah Bapak/Ibu guru menggunakan media } \\
\text { teknologi Pembelajaran saat proses pembelajaran } \\
\text { di kelas? }\end{array}$ & 7 & 4 & 11 \\
2. & $\begin{array}{l}\text { Apakah Bapak/Ibu menggunakan media teknologi } \\
\text { pembelajaran selain ppt ataupun video } \\
\text { pembelajaran? }\end{array}$ & 8 & 11
\end{tabular}




\begin{tabular}{l|l|l|l|l}
3. & $\begin{array}{l}\text { Apakah Bapak/Ibu guru mengetahui Aplikasi } \\
\text { kahoot sebagai media teknologi pembelajaran? }\end{array}$ & 3 & 11 \\
4. & $\begin{array}{l}\text { Apakah Bapak/Ibu bisa menggunakan Aplikasi } \\
\text { Kahoot untuk diterapkan dalam pembelajaran di } \\
\text { kelas? }\end{array}$ & 3 & 8 & 11 \\
\hline
\end{tabular}

Dari hasil survey tersebut menunjukkan bahwa hampir semua guru belum mengetahui aplikasi kahoot dan tidak dapat menggunakan aplikasi kahoot sebagai media pembelajaran di sekolah dasar ataupun di dalam kelas. Setelah kami mengetahui hasil survey tersebut kami memberikan sosialisai penjelasan mengenai aplikasi kahoot, hal ini dilakukan agar para guru dapat memahami dan menggunakkan aplikasi kahoot dalam berbagai kesempatan pembelajaran di kelas. Kami sebagai tim instruktur menjelaskan kepada para guru cara menggunakan Kahoot sebagai media pembelajaran berbasis teknologi di kelas.

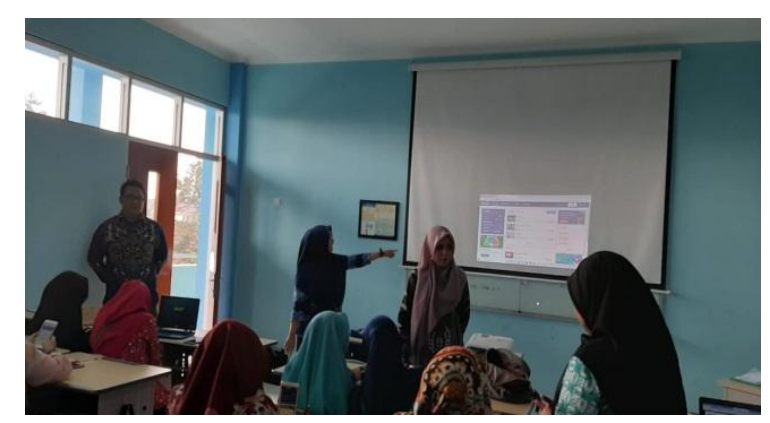

Gambar 2. Saat Sedang Memberikan Penjelasan Kahoot

Pada pelatihan ini tim instruktur memberikan penjelasan dan beberapa praktek langsung dengan materi diantara lain cara membuat dan log in akun kahoot, cara menggunakan aplikasi kahoot sebagai tenaga pendidik dan sebagai peserta didik, dan cara membuat kuis menggunakan aplikasi kahoot. Setelah para peserta memahami penjelasan yang diberikan oleh tim instruktur, selanjutnya peserta langsung diberikan praktek penggunaan aplikasi kahoot. Para peserta mencoba membuat salah satu dari 4 pilihan permainan yang tersedia (kuis, diskusi, survey, dan campuran). Pada media pembelajaran yang akan dibahas adalah Kahoot. Kahoot merupakan permainan pilihan ganda dengan maksimal jumlah pilihan 4 butir jawaban. Pada tampilan soal kuis pilihan ganda bisa memunculkan gambar atau video tergantung dengan bentuk soal yang kita inginkan. Kahoot ini bisa digunakan pada saat pretest sebelum masuk pada materi baru, latihan, post-test, penguatan materi, remedial, pengayaan dan lainnya, yang pasti sebagai variasi dalam menyampaikan materi agar siswa tetap fokus dan minat pada pembelajaran. Baiklah, sebelum memulai membuat Kahoot, kita siapkan dulu daftar soal dan jawaban, gambar atau video pendukung agar memudahkan dalam mengelolanya dikarenakan dalam pembuatan Kahoot harus terkoneksi dengan internet. 


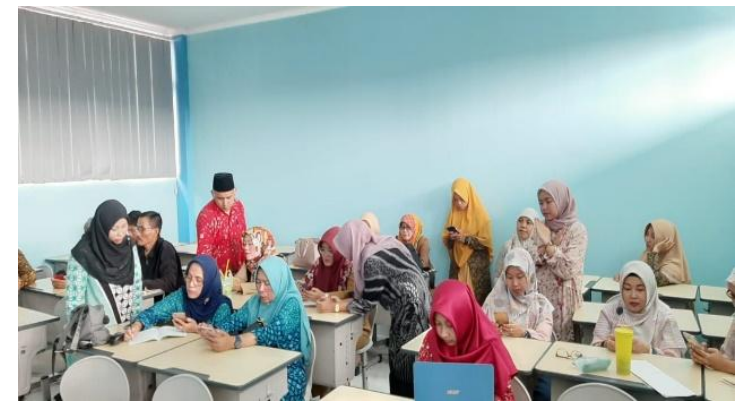

Gambar 3. Mempraktekan Cara Penggunaan Kahoot

Setelah guru diajarkan cara menggunakan Kahoot, guru mengimplementasikannya dikelas masing-masing. Setelah guru mengimplementasikannya, para guru diberikan kuesioner kembali. Kuesioner pertama yang tim instruktur berikan bertujuan untuk mengukur keefektifan aplikasi kahoot sebagai salah satu media pembelajaran di kelas ataupun di Sekolah Dasar, penilaian keefektifan aplikasi kahoot ini meliputi aplikasi kahoot sebagai media pembelajaran, aplikasi kahoot dapat menarik perhatian dan minat belajar bagi peserta didik, dan menjadikan pembelajaran yang efektif, kreatif, serta kondusif. Skala dalam penilaian ini adalah 1 (sangat tidak setuju), 2 (tidak setuju), 3 (ragu-ragu), 4 (setuju), 5 (sangat setuju) dan dari hasil instrument tersebut didapatkan dalam tabel 2 sebagai berikut:

Tabel 2 Hasil Kuesioner Kefektifan Aplikasi Kahoot dalam pembelajaran

\begin{tabular}{|c|c|c|c|c|c|c|c|}
\hline \multirow[t]{2}{*}{ No } & \multirow[t]{2}{*}{ Variabel Penilaian } & \multicolumn{5}{|c|}{ Skala Penilaian } & \multirow[t]{2}{*}{ Total } \\
\hline & & 1 & 2 & 3 & 4 & 5 & \\
\hline 1. & $\begin{array}{l}\text { Apakah anda setuju aplikasi kahoot } \\
\text { sebagai media teknologi } \\
\text { pembelajaran }\end{array}$ & & & & 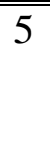 & $\bar{~} 6$ & 11 \\
\hline 2. & $\begin{array}{l}\text { Apakah aplikasi kahoot dapat menarik } \\
\text { perhatian siswa dalam proses } \\
\text { pembelajaran di kelas }\end{array}$ & & & & 6 & 5 & 11 \\
\hline 3. & $\begin{array}{l}\text { Apakah penggunaan aplikasi kahoot } \\
\text { dapat menumbuhkan pembelajaran yang } \\
\text { kreatif }\end{array}$ & & & 2 & 5 & 4 & 11 \\
\hline 4. & $\begin{array}{l}\text { Apakah penggunaan aplikasi kahoot } \\
\text { menjadikan suatu pembelajaran yang } \\
\text { efektif pada proses pembelajaran di } \\
\text { kelas }\end{array}$ & & & & 7 & 4 & 11 \\
\hline 5. & $\begin{array}{l}\text { Apakah penggunaan aplikasi kahoot } \\
\text { dapat menjadikan kelas kondusif }\end{array}$ & & & 1 & 8 & 2 & 11 \\
\hline 6. & $\begin{array}{l}\text { Apakah aplikasi kahoot menjadikan } \\
\text { proses belajar mengajar menjadi } \\
\text { menyenangkan }\end{array}$ & & & & 9 & 2 & 11 \\
\hline 7. & $\begin{array}{l}\text { Apakah dengan aplikasi kahoot yang } \\
\text { digunakan menjadikan minat peserta } \\
\text { didik bertambah dalam proses } \\
\text { pembelajaran di kelas }\end{array}$ & & & & 6 & 5 & 11 \\
\hline
\end{tabular}


Berdasarkan hasil penilaian keefektifan aplikasi kahoot dalam pembelajaran di sekolah dasar menunjukkan bahwa aplikasi kahoot sangat efektif digunakan dalam proses pembelajaran di sekolah dasar dan dapat memberikan pembelajaran yang kreatif dan menyenangkan. Pada tahap akhir tim instruktur memberikan kuesioner kembali sebagai pengukur dalam menilai keberhasilan program yang telah diberikan. Dalam kuesioner ini tim intruktur menggunakan skala penilian yang terdiri dari 1 (tidak memuaskan), 2 (kurang memuaskan), 3 (cukup memuaskan), 4 (memuaskan), 5 (sangat memuaskan). Hasil penilaian menunjukkan bahwa program sosialisasi pelatihan ini telah dilaksanakan sangat baik dan memberikan kepuasan tersendiri bagi para peserta yang hadir.

Tabel 3. Hasil penilaian pelatihan

\begin{tabular}{|c|c|c|c|c|c|c|c|}
\hline \multirow[t]{2}{*}{ No } & \multirow[t]{2}{*}{ Variabel Penilaian } & \multicolumn{5}{|c|}{ Skala Penilaian } & \multirow[t]{2}{*}{ Total } \\
\hline & & 1 & 2 & 3 & 4 & 5 & \\
\hline 1. & $\begin{array}{l}\text { Efisien waktu yang diberikan dalam } \\
\text { pelatihan }\end{array}$ & & & & 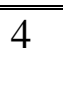 & 7 & 11 \\
\hline 2. & Kualitas isi materi pelatihan & & & & 6 & 5 & 11 \\
\hline 3. & $\begin{array}{l}\text { Sarana dan prasarana di tempat } \\
\text { pelatihan }\end{array}$ & & & 1 & 7 & 3 & 11 \\
\hline 4. & Kesiapan narasumber & & & & 7 & 4 & 11 \\
\hline 5. & Pelayanan yang diberikan tim instruktur & & & & 3 & 8 & 11 \\
\hline
\end{tabular}

Namun sarana prasarana di tempat pelatihan perlu diperbaiki dan ditingkatkan karena ada penilaian cukup yang diberikan oleh satu responden. Para pserta juga memberikan masukan kepada para tim instruktur dan penyelenggara agar kedepannya pelatihan seperti ini dapat diberikan kembali kepada guru-guru dan juga peseta didik agar aplikasi kahhot ini dapat diimplementasikan dengan baik di dalam proses pembelajaran.

\section{Kesimpulan}

Penelitian ini bertujuan guna menguji hipotesis yaitu apakah media pembelajaran berbasis teknologi Kahoot efektif digunakan oleh guru Sekolah Dasar Sukabumi Jawa Barat dalam proses belajar mengajar di sekolah. Hasil dari penelitian menyatakan bahwa media pembelajaran berbasis teknologi efektif digunakan oleh guru Sekolah Dasar Sukabumi Jawa Barat. Namun terdapat kendala yakni waktu yang terbatas saat proses belajar mengajar dan masih terdapat beberapa guru yang belum bisa menggunakan Kahoot.

\section{Daftar Pustaka}

[1] Nugrahenny, D., Wintolo, H., Kusumaningrum, A., Sudaryanto, S., \& Sajati, H. (2019). Pendampingan Pengenalan Metode Pengetikan Cepat Menggunakan Microsoft Word Bagi Siswa Kelas 5 SD IT Salsabila Al Muthi'in Yogyakarta. KACANEGARA Jurnal Pengabdian pada Masyarakat, 2(1), 21-28.

[2] Rianto, R., \& Wardana, A. K. (2019). Pelatihan Microsoft Office Sebagai Upaya Pengembangan dan Peningkatan Kemampuan Penggunaan Aplikasi Pengolah Kata Dan Angka Bagi Guru PAUD Al Muthi'in Yogyakarta. KACANEGARA Jurnal Pengabdian pada Masyarakat, 2(2), 99-104. 
[3] Pertiwi, D. R. (2019). Pendampingan Pengembangan Kemampuan Story Telling Guru Kelompok Bermain Dan Taman Penitipan Anak Aviciena. KACANEGARA Jurnal Pengabdian pada Masyarakat, 2(2), 105-109.

[4] Siregar, J. R. (2014). Peningkatan Keterampilan Guru Menggunakan Media Pembelajaran Melalui Lesson Study Di Sman 04 Merlung Kabupaten Tanjung Jabung Barat Propinsi Jambi (Doctoral dissertation, UNIMED).

[5] Munadi, Y. (2008). Media Pembelajaran. Jakarta: Gaung Persada (GP) Press.

[6] Azhar, A. (2007). Media pembelajaran, Jakarta: PT. Raja Grafindo Persada, 15-85.

[7] Ayuningtyas, A., Honggowibowo, A. S., Pujiastuti, A., Retnowati, N. D., \& Indrianingsih, Y. (2018). Pendampingan Pembuatan Bahan Ajar Bagi Guru Sekolah Dasar Islam Terpadu (SDIT) Salsabila Al Muthi'in Berbasis Multimedia dengan Menggunakan Microsoft Power Point. KACANEGARA Jurnal Pengabdian pada Masyarakat, 1(1), 1-6.

[8] Rafnis, R. (2019). Pemanfaatan Platform Kahoot Sebagai Media Pembelajaran Interaktif. $e$ Tech: Jurnal Ilmiah Teknologi Pendidikan, 6(2).

[9] Putri, A. R., \& Muzakki, M. A. (2019). Implementasi Kahoot Sebagai Media Pembelajaran Berbasis Digital Game Based Learning Dalam Menghadapi Revolusi Industri 4. 0. In Prosiding Seminar Nasional, hlm (pp. 218-223).

[10] Correia, M., \& Santos, R. (2017, November). Game-based learning: The use of Kahoot in teacher education. In 2017 International Symposium on Computers in Education (SIIE) (pp. 1-4). IEEE.

[11] Dewi, C. K., \& Mujib, M. (2018). Alat Evaluasi Menggunakan Kahoot pada Pembelajaran Matematika Kelas X. Indonesian Journal of Science and Mathematics Education, 1(2), 163-171. 